\title{
Action Taken with Study Treatment
}

National Cancer Institute

\section{Source}

National Cancer Institute. Action Taken with Study Treatment. NCI Thesaurus. Code C49499.

The reason that changes were made to the specific therapy under study. 